Article

\title{
Designing Dual-Effect Nanohybrids for Removing Heavy Metals and Different Kinds of Anions from the Natural Water
}

\author{
Osama Saber ${ }^{1, *(\mathbb{D})}$, Sarah Mousa Asiri ${ }^{2}$, Mohamed Farouk Ezzeldin ${ }^{3}$, Waleed I. M. El-Azab ${ }^{4}$ \\ and Mohammed Abu-Abdeen ${ }^{5}$ \\ 1 Department of Physics, College of Science, King Faisal University, P.O. Box 400, Al-Ahsa 31982, Saudi Arabia \\ 2 Department of Biophysics, Institute for Research and Medical Consultations (IRMC), Imam Abdulrahman \\ Bin Faisal University (IAU), P.O. Box 1982, Dammam 31441, Saudi Arabia; smasiri@iau.edu.sa \\ 3 Department of Environmental Health, Collage of Public Health, Imam Abdulrahman Bin Faisal \\ University (IAU), P.O. Box 1982, Dammam 31441, Saudi Arabia; mfezzeldin@iau.edu.sa \\ 4 Egyptian Petroleum Research Institute, Nasr City, P.O. Box 11727, Cairo 11765, Egypt; welazab@yahoo.com \\ 5 Physics Department, Faculty of Science, Cairo University, Giza 12613, Egypt; mmaabdeen@sci.cu.edu.eg \\ * Correspondence: osmohamed@kfu.edu.sa; Tel.: +966-13-589-9440
}

Received: 29 April 2020; Accepted: 28 May 2020; Published: 1 June 2020

check for updates

\begin{abstract}
In the present study, well-designed nanohybrids are used to act as effective dual-function adsorbents for removing both anions and heavy metals from natural water, at the same time. In this trend, $\mathrm{Zn}-\mathrm{Al} \mathrm{LDHs}$ and graphene oxide are applied to build up building blocks to produce a series of nanohybrids. These nanohybrids were characterized by X-ray diffraction, thermal analyses, Fourier transform infrared spectroscopy, Raman spectroscopy, and scanning and transmission electron microscopy. These techniques confirmed that the prepared nanohybrids contained nanolayered structures with three-dimensional porous systems. These porous systems were identified by the nitrogen adsorption-desorption isotherms and water purification experiments. The obtained results indicated that these nanohybrids included suitable structures to act as dual function materials. The first function was achieved by removing more than $80 \%$ of both cadmium and lead from the natural water. The second function was accomplished by eliminating of $100 \%$ of hydrogen phosphate and bromide anions alongside with $80 \%-91 \%$ of sulfate, chloride, and fluoride anions. To conclude, these well-designed nanohybrids convert two-dimensional nanolayered structures to three-dimensional porous networks to work as dual-function materials for removing of heavy metals and different kinds of anions naturally found in the fresh tap water sample with no parameters optimization.
\end{abstract}

Keywords: adsorption process; dual-function materials; graphene-nanohybrids; porous structures; water quality

\section{Introduction}

It is well known that the quality of drinking water plays an important role in public health of a community. Therefore, the chemical composition of surface water and groundwater, as sources of fresh water supply, is considered a critical issue for water quality [1]. One of the main problems of these water resources is the probability of contamination by several kinds of pollutants such as heavy metals and inorganic anions due to anthropogenic and/or natural activities [2]. The presence of heavy metals in water creates serious human health and environmental issues due to potentially rising toxicity [3]. Lead and cadmium are common examples of heavy metals that threat human health [4]. Concentrations of $1 \mu \mathrm{g} / \mathrm{L}$ of cadmium and $5 \mu \mathrm{g} / \mathrm{L}$ of lead in drinking water could cause fetal diseases 
like brain and kidney damage to a certain community [5]. The control and removal of excess inorganic anions (such as fluoride, sulfate, hydrogen phosphate, chloride and bromide) in water and wastewater is an essential goal in environmental supervision. The undesirable impacts of these anions, not only on human health and natural ecosystems but also on water network pipelines and treatment facilities over both the short and long term were indicated [6-9]. Consequently, the development of new techniques to remove heavy metals and inorganic anions from water has become a vital requirement.

Recently, many beneficial processes such as electrocoagulation, sorption and electrochemical separation have been employed to remove several types of pollutants from aqueous mediums [10]. However, many researchers believe that the adsorption process shows satisfactory results in removing of such pollutants because of its low cost, easy operation, and proper efficiency [11]. Among the low-cost adsorbents investigated over the past few years, different kinds of volcanic ash, algae, clay soils, chitin, agricultural wastes, sewage sludge, metallic hydroxides, sludge and industrial wastes were noteworthy [11]. Unfortunately, the majorities of these materials are effective for eliminating only one kind of anion even though some other anions as well as heavy metals might be found in the same matrix. Additionally, these effective adsorbents may not be suitable for all anions because they differ in sizes and valences.

Therefore, the current study focuses on designing dual-function materials to be effective for removing both anions and heavy metals at the same time from real water. These materials were built by combining two building blocks together into well-designed nanostructures. Layered double hydroxide $(\mathrm{LDH})$ and graphene sheets are suitable as building blocks for producing the dual-function nanostructures.

In one hand, LDHs are inorganic layered materials with a general formula of $\left[\mathrm{MII}_{1-\mathrm{x}} \mathrm{MIII}_{\mathrm{x}}(\mathrm{OH})_{2}\right]^{\mathrm{x}+}(\mathrm{A})^{\mathrm{n}-} \mathrm{x} / \mathrm{n} \cdot \mathrm{mH}_{2} \mathrm{O}$, where MII and MIII are di-valent and tri-valent cations; respectively and $\mathrm{A}^{\mathrm{n}-}$ is the interlayered anion $[12,13]$. In the last few decades, LDH markedly received interest for their potential applications in different area, because of their unique properties. High sorption efficiency, low-cost, simple production, and many other benefits make these materials favorable for water purification applications [14]. LDHs materials were also studied as scavengers and sorbents of metal cations from water [15]. On the other hand, graphene (G) and graphene oxide (GO) are one atom-thick carbon layer in a hexagonal lattice in two dimensional spaces with a special kind of compounds and exceptional properties that are technologically interesting [16]. The combination between LDHs and graphene builds up a unique structure of complex composites that takes full benefits of both materials.

Goh et al. [14] investigated uptake of arsenate $\mathrm{As}(\mathrm{V})$ from water by nano-crystalline $\mathrm{Mg}-\mathrm{Al}$ hydrotalcites with various desorption/sorption conditions. Ni-Al LDH/graphene was prepared by $\mathrm{Li}$ et al. [15], for the high adsorption capacities of sodium, arsenite, and arsenate. Gonazlez et al. [17] reported that LDHs show high adsorption capacity to remove copper cations. It was mentioned that $\mathrm{LDH} /$ graphene nanocomposites are superior adsorbents for the heavy metals compared with the pristine LDH or graphene [18]. The calcined MgAl-LDH/graphene presented higher adsorption capacity in removing of $\mathrm{Cr}(\mathrm{VI})$ from water. Although these various applications of GO-LDHs composites in the field of eliminating of heavy metals, dyes and some organic pollutants from aqueous media were published [10-18]. Most of these studies focused only on a single pollutant and are usually found in a synthetic matrix [16]. Consequently, verification of these hybrid materials under natural conditions using real samples that involve multiple elements is widely required.

Therefore, the current study aims to prepare a set of dual-function nanohybrids to remove different kinds of inorganic anions and some heavy metals from natural water of the national network of Eastern providence of Saudi Arabia. These nanohybrids are based on the nanolayered structures of $\mathrm{Zn}-\mathrm{Al}$ LDHs and graphene oxide. This target can be completed through marriage with two building blocks together into well-designed nanostructures. Certainly, layered double hydroxide (LDH) and graphene sheets are suitable for building blocks to produce the dual-function nanohybrids. 
In this trend, $\mathrm{Zn}-\mathrm{Al} \mathrm{LDHs}$ are prepared and doped by the prepared graphene oxide to build new micro-porous and meso-porous structures through growths of the nanolayers of LDHs on the nanosheets of graphene oxide. In order to maximize the efficiency of these nanohybrids, different percentages of graphene oxide are used to obtain the optimum percentage of graphene oxide for improving the texture of $\mathrm{Zn}-\mathrm{Al}$ LDHs. Surface properties of the prepared nanohybrids are measured and compared with the pure $\mathrm{Zn}-\mathrm{Al}$ LDHs. The prepared nanohybrids are also characterized by X-ray diffraction, Fourier Transform Infrared Spectroscopy and Raman Spectroscopy. In addition, a morphological study is investigated through scanning electron microscopy and transmission electron microscopy. The prepared nanohybrids are applied to remove monovalent anions such as: fluoride, chloride, and bromide alongside with di-valent and tri-valent anions such as sulfate and hydrogen phosphate from the natural water. In order to indicate the dual-function effect of the prepared nanohybrids, these materials are applied to remove the heavy metals (cadmium and lead) from the same water sample.

Hence, based to the best knowledge of the authors, the current work would count as a pioneer study for applying nanohybrids as a dual-function adsorbent for removing different kinds of anions as well as cations such as heavy metals in real fresh water.

\section{Materials and Methods}

\subsection{Preparation of Graphene Sheets}

The nanosheets of graphene were prepared by the electrochemical cell as shown in Figure 1. This electrochemical cell used graphite rods as cathode and anode in aqueous solution of imidazolium (ionized liquid) as an electrolyte. During the electrochemical process, water molecules were dissociated and oxidized to produce $\cdot \mathrm{OH}$ radicals in the presence of graphite rods as a catalyst. These radicals were started to bombard the anode by producing graphene sheets which can act as a catalyst. This catalytic effect of the graphene sheet caused simultaneous generation of the hydroxyl radical to accelerate production of graphene sheets through the exfoliation process of graphite [16]. The black product of graphene sheets were separated and washed by ethyl alcohol and then dried at $80^{\circ} \mathrm{C}$.

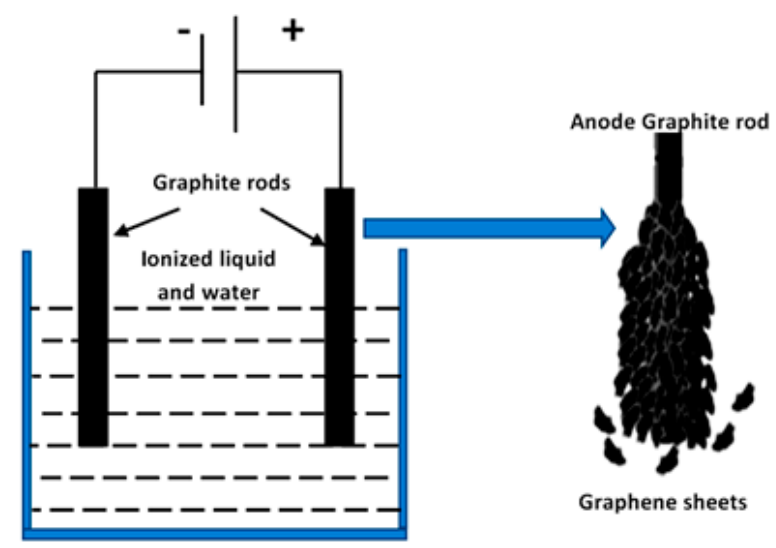

Figure 1. Schematic presentation of the electrochemical cell for producing graphene sheets through the exfoliation process of the graphite anode.

\subsection{Preparation of Nanohybrids}

In order to avoid hydrophobic behavior of the graphene sheets, they were oxidized through the reaction with hydrogen peroxide in ultrasonic bath. A total of $0.6 \mathrm{~g}$ of graphene was suspended in $500 \mathrm{~mL}$ of water and $100 \mathrm{~mL}$ of hydrogen peroxide (30\%) for $2 \mathrm{~h}$. The nanohybrid (NH1) was prepared by the reaction of $0.05 \mathrm{~mol}$ of zinc nitrate hexahydrate $\mathrm{Zn}\left(\mathrm{NO}_{3}\right)_{2} \cdot 6 \mathrm{H}_{2} \mathrm{O}$ with $0.02 \mathrm{~mol}$ of aluminum nitrate hexahydrate $\mathrm{Al}\left(\mathrm{NO}_{3}\right)_{3} \cdot 9 \mathrm{H}_{2} \mathrm{O}$ in the presence of $0.05 \mathrm{~mol}$ of urea $\mathrm{CO}\left(\mathrm{NH}_{2}\right)_{2}$. This reaction was achieved in the presence of $0.11 \mathrm{~g}$ of the oxidized form of graphene suspended in $750 \mathrm{~mL}$ of deionized 
water. The reaction occurred at $80^{\circ} \mathrm{C}$ in the water bath. The grey-white product was precipitated and washed several times by deionized water after $24 \mathrm{~h}$.

Another two nanohybrids were prepared via the same procedure by decreasing the content of graphene oxide. The reaction of zinc nitrate, aluminum nitrate and urea was completed in the presence of $0.07 \mathrm{~g}$ and $0.04 \mathrm{~g}$ of graphene oxide to produce two new nanohybrids $\mathrm{NH} 2$ and $\mathrm{NH} 3$; respectively. For comparison, Zn-Al-layered double hydroxide was prepared by the same method without adding graphene oxide.

\subsection{Characterization}

The crystalline structures of $\mathrm{Zn}-\mathrm{Al} \mathrm{LDH}$ and the new nanocomposites were confirmed by X-ray diffraction (XRD-7000, Shimadzu, Kyoto, Japan, with monochromatic high-intensity Cu K $\alpha$ radiation $(\lambda=1.5406 \AA)$ ) by a scan rate of $0.5^{\circ} / \mathrm{min}$. The functional groups were recorded through Fourier Transform Infrared Spectroscopy (FTIR) over the wave number range $400-4000 \mathrm{~cm}^{-1}$, using "Spectrum Two" from PerkinElmer Co. The morphology, shape surface and distribution of the samples were obtained directly at room temperature using Scanning Electron Microscope (SEM, Inspect S50, FEI Company, Tokyo, Japan). Transmission Electron Microscopy (TEM, JEM 2100F, JEOL Company, Tokyo, Japan) was carried out at room temperature with an acceleration voltage of 200 kV. Raman spectra measurements were performed using LabRAM HR Evolution, Horiba-Jobin Yvon Technology, with laser 633 ULF. The grating groove density was 300 grooves $/ \mathrm{mm}$. The methods of Brunauer-Emmett-Teller (BET) and Barrett-Joyner-Halenda (BJH) were adopted to determine the material surface area, pore volume, and pore size distribution. Inductively coupled plasma emission spectroscopy (ICPE-9800, Shimadzu, Kyoto, Japan) and ion chromatography (930 Compact IC Flex, Metrohm, Riverview, FL, USA) were employed to analyze the concentration of ions in solutions.

\subsection{Adsorption Experiment}

The removal efficiency RE (\%) of the samples was investigated at room temperature. Typically, a weight $(\mathrm{g})$ of the sample was stirred in a volume $\mathrm{V}(\mathrm{L})$ of fresh tap water (from a national network system) at $\mathrm{pH} 6$ up to $5 \mathrm{~h}$ to prepare constant concentrations $\mathrm{W} / \mathrm{V}(10 \mathrm{~g} / \mathrm{L})$ of aqueous solutions. In order to study the effect of the adsorbent amount, two other concentrations $(20 \mathrm{~g} / \mathrm{L}$ and $30 \mathrm{~g} / \mathrm{L})$ were also used. Before achieving equilibrium, the concentrations of ions in solution were tested every hour. After equilibrium, the suspension was separated by centrifugation, and then the residual concentrations of cations and anions were determined by inductively coupled plasma mission spectroscopy (ICPE) and ion chromatography (IC) as shown in Figure S1. Removal efficiency RE (\%) was calculated using the following formula [14].

$$
\operatorname{RE}(\%)=\left(C_{i}-C_{f}\right) / C_{i} \times 100
$$

where $C_{i}$ and $C_{f}(m g / L)$ is the initial and final concentrations of ions, respectively.

\section{Results}

\subsection{Powder X-Ray Diffraction}

The crystalline structures of the prepared materials were determined by the powder X-ray diffraction technique as shown in Figure 2. In Figure 2a, the main peak was observed at 2-theta $26.7^{\circ}$ which is an indication for the graphene structure. The weak peak, observed at 2-theta $42.9^{\circ}$, confirmed the graphene structure. Both peaks agreed with the reflections of carbon layers in the planes [002] and [100] of graphene. The plane reflection of [002] was used for determining the orientation of the carbon rings in graphene, while, the plane reflection of [100] was due to the condensation degree of the carbon rings in graphene $[19,20]$. The treated layers of graphene were also confirmed by the appearance of two peaks at 2-theta $21.8^{\circ}$ and $24.2^{\circ}$ as shown in Figure 2a.

The nanolayered structure of the prepared $\mathrm{Zn}-\mathrm{Al} \mathrm{LDH}$ was confirmed by the $\mathrm{X}$-ray diffraction pattern shown in Figure $2 b$ where, symmetric and sharp peaks were observed at low 2 -theta. The peaks 
aligned with d-spacing of $0.76 \mathrm{~nm}, 0.38 \mathrm{~nm}$ and $0.26 \mathrm{~nm}$. Additionally, asymmetric and weak peaks were detected at high 2-theta which agreed with $0.23 \mathrm{~nm}, 0.19 \mathrm{~nm}, 0.17 \mathrm{~nm}$ and $0.15 \mathrm{~nm}$. These d-values were due to the planes reflection [003], [006], [009], [012], [015], [110] and [113] of Zn-Al-carbonate LDH (JCPDS file No. 48-1022) [21-24]. The parameters of the unit cell of the prepared LDH (a) and (c) were calculated by the equations: $a=2 \times d$-value of plane [110] and $c=3 \times d$-value of plane [003], respectively. These parameters were $0.310 \mathrm{~nm}$ and $2.280 \mathrm{~nm}$ similar to our results previously published for LDHs [21].

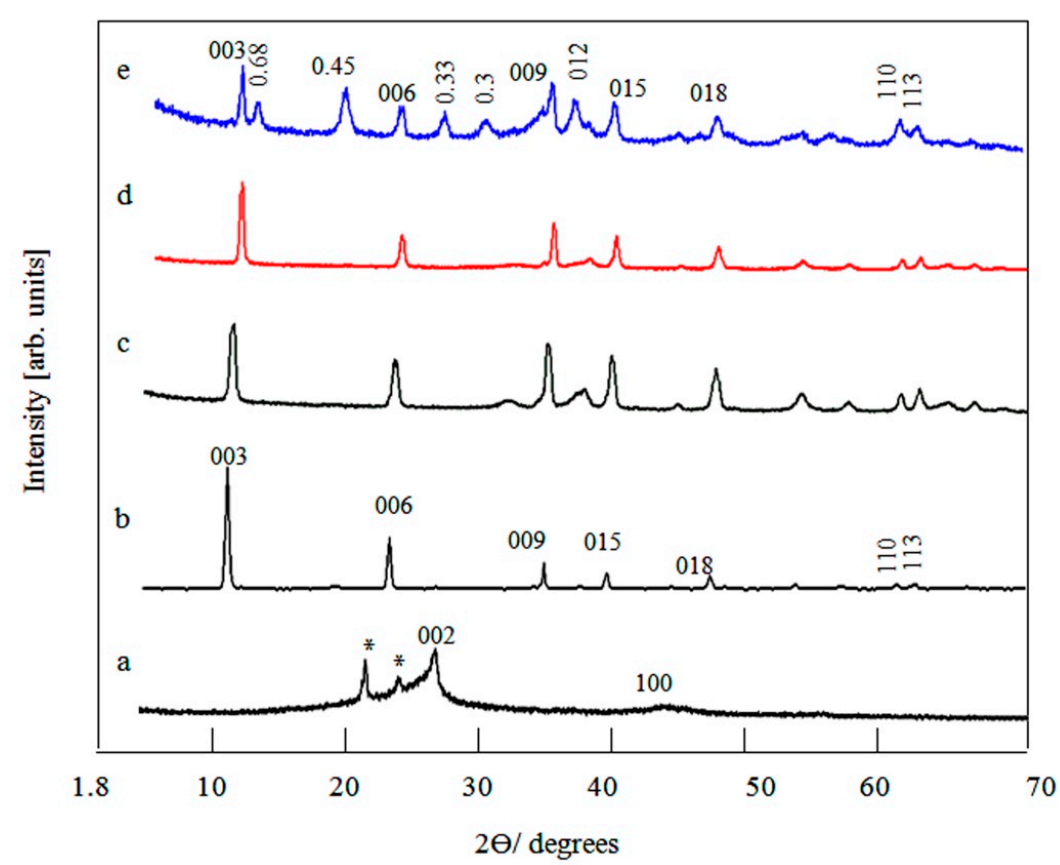

Figure 2. X-ray diffractions of (a) the prepared graphene, (b) Zn-Al LDH, (c) nanohybrid NH1, (d) nanohybrid NH2 and (e) nanohybrid NH3. ${ }^{*}$ the peaks for the treated graphene.

The X-ray diffraction patterns of the prepared nanohybrids $\mathrm{NH} 1, \mathrm{NH} 2$ and $\mathrm{NH} 3$ are displayed in Figure 2c-e. In case of the nanohybrid NH1, clear peaks were observed at 2-theta 11.8, 24.6, 34.7, $37.4,39.3,60.3$, and 61.6. These peaks were similar to the reflections of the main planes of the prepared Zn-Al LDH [003], [006], [009], [012], [015], [110], and [113]. It means that the nanohybrid NH1 included nanolayered structure whereas the diffraction lines obtained for NH1 were identified as an LDH structure by fitting and matching with the standard entire diffraction pattern of JCPDS 48-1022 as shown in Figure 2c. These diffraction lines exhibited broad peaks. The broadness of diffraction lines showed that the crystallinity of NH1 was in a nanoscale with a layered structure. Although the nanohybrid $\mathrm{NH} 1$ contained $3.5 \%$ of graphene oxide, the characteristic peaks of graphene oxide were not clear in the pattern. It indicated that the sheets of graphene oxide were completely combined and covered with the structure of LDH.

By decreasing the content of graphene oxide to $2.5 \%$, Figure $2 \mathrm{~d}$ showed the $\mathrm{X}$-ray diffraction pattern of the nanohybrid NH2. It indicated that the nanohybrid NH2 contained a layered structure with the same characteristic peaks of LDH. However the peaks of graphene oxide were not visile in Figure 1d. It confirmed that graphene oxide sheets were completely dispersed in the matrix of the nanolayered structure of LDH.

Due to continuous reduction of the graphene oxide content to $1.3 \%$, three series of layered structures were observed in the X-ray diffraction of the nanohybrid NH3 as shown in Figure 2 e. The d-values $0.750 \mathrm{~nm}, 0.370 \mathrm{~nm}$ and $0.250 \mathrm{~nm}$ were found in the first layered structure. The second layered structure included the values $0.680 \mathrm{~nm}, 0.330 \mathrm{~nm}$ and $0.230 \mathrm{~nm}$. These series agreed with the reflections of $\mathrm{d} 003, \mathrm{~d} 006$, and $\mathrm{d} 009$ and indicated that $\mathrm{d} 003=2 \times \mathrm{d} 006=3 \times \mathrm{d} 009$. The third 
phase was observed at $0.450 \mathrm{~nm}$ and $0.300 \mathrm{~nm}$. These reflections included the planes 006 and 009, which were produced from intercalating the single nanosheets of graphene oxide among the nanolayers of LDHs to appear as a sandwich-type structure of LDHs. These reflections agreed with $2 \times \mathrm{d} 006=3 \times \mathrm{d} 009(2 \times 0.450 \mathrm{~nm}=3 \times 0.300 \mathrm{~nm})$. These results indicated that the nanohybrid NH3 included three different phases of layered structures. It pointed out that the presence of a low percentage of graphene caused growth of different kinds of combinations between the sheets of graphene oxides and the layers of LDH.

The current data represented that graphene oxide played an important role for building up the nanolayered structure of the prepared nanohybrids. The nanohybrids NH1 and NH2 obtained one kind of nanolayered structure while three kinds of nanolayered structures were observed for the nanohybrid NH3. In order to explain this finding, we will discuss the dispersion of the nanosheets of graphene oxide during the growth process of LDH nanolayers. In the case of the nanohybrids NH1 and $\mathrm{NH} 2$, the high percentages of graphene oxide exist as groups when building up their nanolayered structures because of their aggregation behavior. It caused formation of one kind of combination between LDH layers with the nanosheets of graphene oxide. For the nanohybrid NH3, the low percentage of graphene oxide gave high dispersion in the medium. Therefore, their nanosheets exist as a single, few and/or groups. During growth of the nanolayers of LDH, three different kinds of interactions occurred with the nanosheets of graphene oxide while producing three different kinds of nanolayered structures. This description was confirmed by analyzing TEM images and surface measurement (will be discussed later).

Another effect was observed for graphene oxide on the crystal size of the LDH layers because of the considerable broadened diffraction peaks of the prepared nanohybrids. Thus, the Debye-Scherer equation was applied to calculate the crystals size of the nanohybrids NH1, NH2 and NH3. According to the peaks of the planes 003, 006 and 009, the mean crystal size of the nanohybrid NH1 was calculated to be $17.0 \mathrm{~nm}$. In case of both NH2 and NH3, they became $26.0 \mathrm{~nm}$ and $15.0 \mathrm{~nm}$, respectively. However, the calculations of the pure $\mathrm{Zn}-\mathrm{Al} \mathrm{LDHs}$ showed that its crystal size was $74.40 \mathrm{~nm}$. It highlighted that the presence of graphene sheets played vital role for production platelets of LDHs in the nano scale, which is in agreement with our previous studies for producing nanolayers of LDHs using carbon nanotubes [21].

\subsection{Scanning Electron Microscopy and Energy-Dispersive X-Ray Spectrometry}

It is known that graphene consists of a two-dimensional structure. Therefore, SEM images of the prepared graphene exhibited plate-like morphology as shown in Figure 3a,b. SEM images also revealed strong aggregates for the graphene sheets. This assembling behavior was due to strong intermolecular interactions among the carbon sheets.
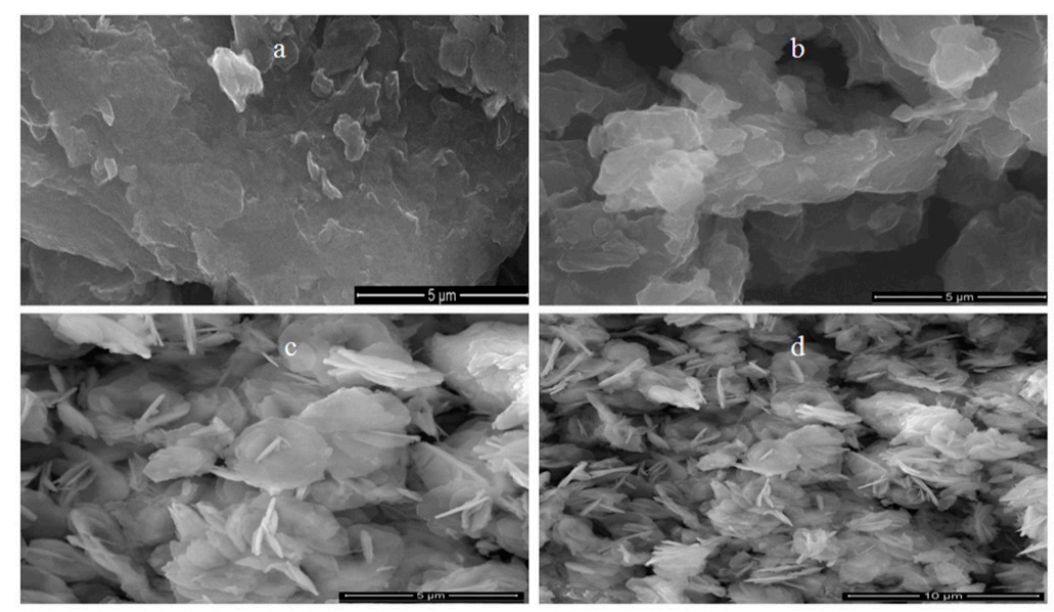

Figure 3. Scanning electron microscopy (SEM) images of (a,b) prepared graphene and (c,d) nanohybrid NH1. 
SEM images in Figure 3c,d showed the morphology of the nanohybrid NH1. It exhibited individual plates of LDH that included different orientations. This characteristic led to building a porous structure. Although LDH structure is a two-dimensional material, the growth of the LDH layers in presence of graphene oxide converted the nanohybrid NH1 to become a three-dimensional porous structure as shown in Figure 3c,d.

By decreasing the content of graphene oxide, SEM images of the nanohybrid NH2 revealed very small aggregates looking like nanoflowers as shown in Figure 4a. By magnification, Figure 4 b showed that these aggregates included cross-linked characteristics of three-dimensional nanoflowers with smooth nanoplates. In case of the nanohybrid NH3, SEM images revealed different types of aggregates, as shown in Figure 4c. These aggregates indicated that there were different kinds of interactions and combinations between layers of LDH and graphene sheets. Additionally, Figure $4 \mathrm{~d}$ showed that the growth of the nanolayers of LDHs over the graphene nanosheets produced 3D-nanoflowers.

Energy-dispersive $X$-ray spectrometry (EDX) analysis indicated local data of the different elements in the outermost layers of the platelet of the nanohybrids. Zinc, aluminum, carbon and oxygen were clearly identified in the nanohybrids NH1 and NH3. Figure 5 showed that the carbon peak was clearer in the nanohybrid NH1 in comparison to nanohybrid NH3, because of higher content of graphene oxide in the nanohybrid NH1.
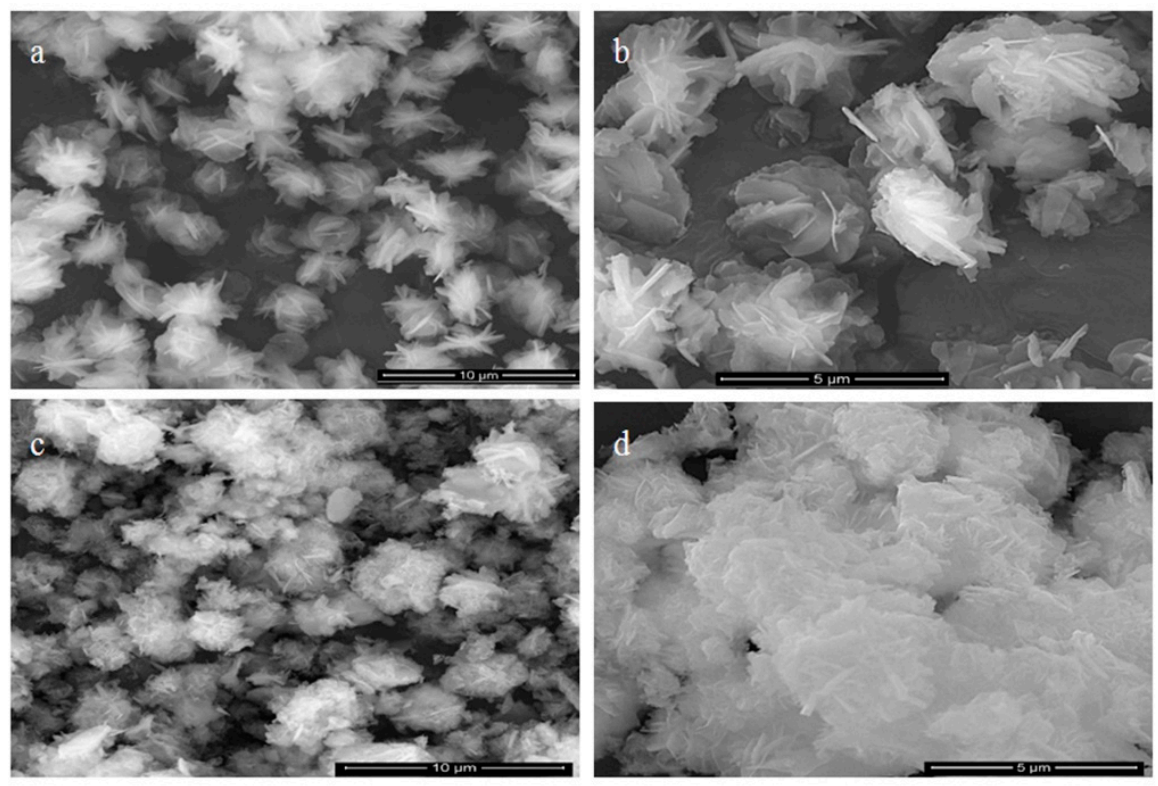

Figure 4. SEM images of $(\mathbf{a}, \mathbf{b})$ nanohybrid $\mathrm{NH} 2$ and $(\mathbf{c}, \mathbf{d})$ nanohybrid $\mathrm{NH} 3$.

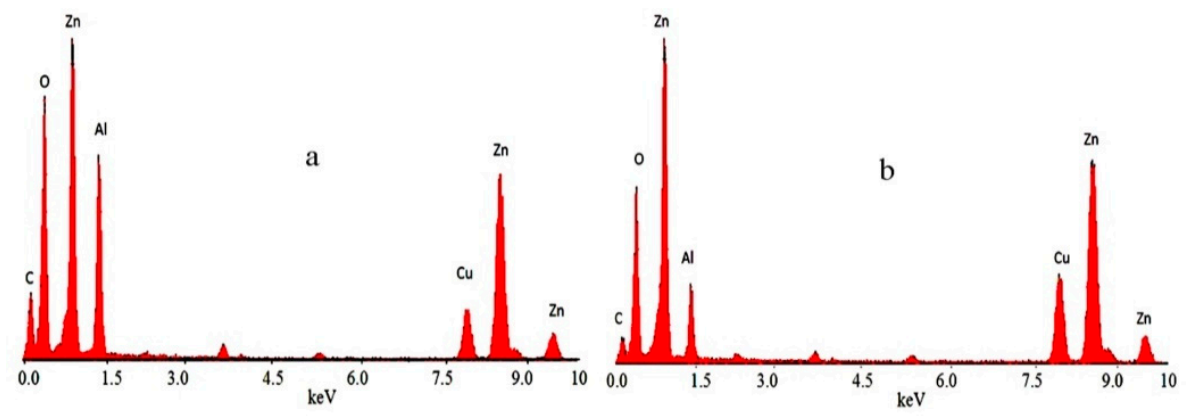

Figure 5. Energy-dispersive X-ray (EDX) spectra of (a) nanohybrid NH1 and (b) nanohybrid NH3.

\subsection{Transmission Electron Microscopy}

It is known that graphene is a single layer of graphite. Consequently, TEM images of the prepared graphene revealed individual and multi-layers in the nano scale as shown in Figure 6a,b. Figure 6a 
presented large sheets similar to crumpled silk veil, as previously published in the literature [25]. The thin and fine sheets of graphene were observed in Figure $6 \mathrm{~b}$.
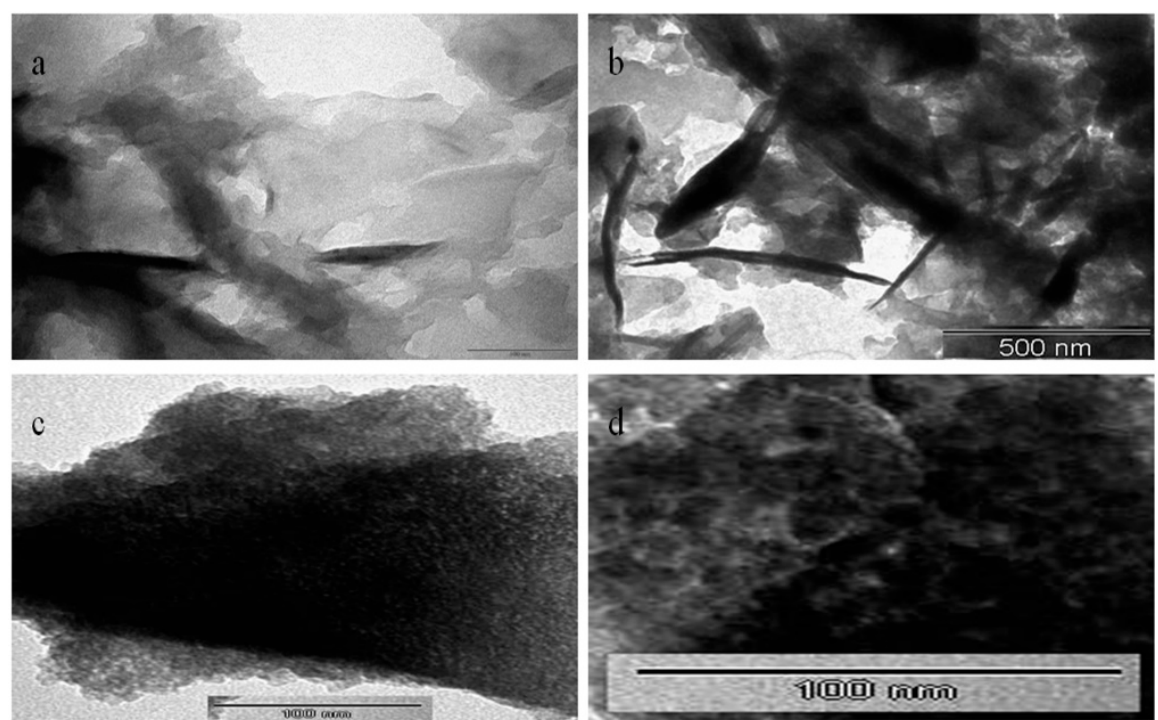

Figure 6. Transmission electron microscopy (TEM) images of $(\mathbf{a}, \mathbf{b})$ prepared graphene and (c,d) nanohybrid NH1.

Due to the combination of graphene oxide with $\mathrm{LDH}$, new structures of nanohybrids were released as presented in Figure $6 c, d$. Figure $6 c$ expressed strong aggregates for the nanohybrid NH1. By magnification, a clear porous structure was observed for the nanohybrid NH1 in Figure $6 \mathrm{~d}$. Moreover, transmission electron microscopy (TEM) images of the nanohybrid NH2 revealed the same aggregates as seen in Figure 7a,b. These aggregates were formed by growing the nanolayers of LDH to be curled and perpendicular to the sheets of graphene oxide while producing a 3D-porous structure looking like a nest as shown in Figure 7a. By magnification, TEM images confirmed this explanation because of nanoplatelets of LDH over the graphene sheet that appeared in Figure $6 \mathrm{~b}$. In case of the nanohybrid NH3, Figure 7c,d displayed multilayer agglomerates with irregular shapes.
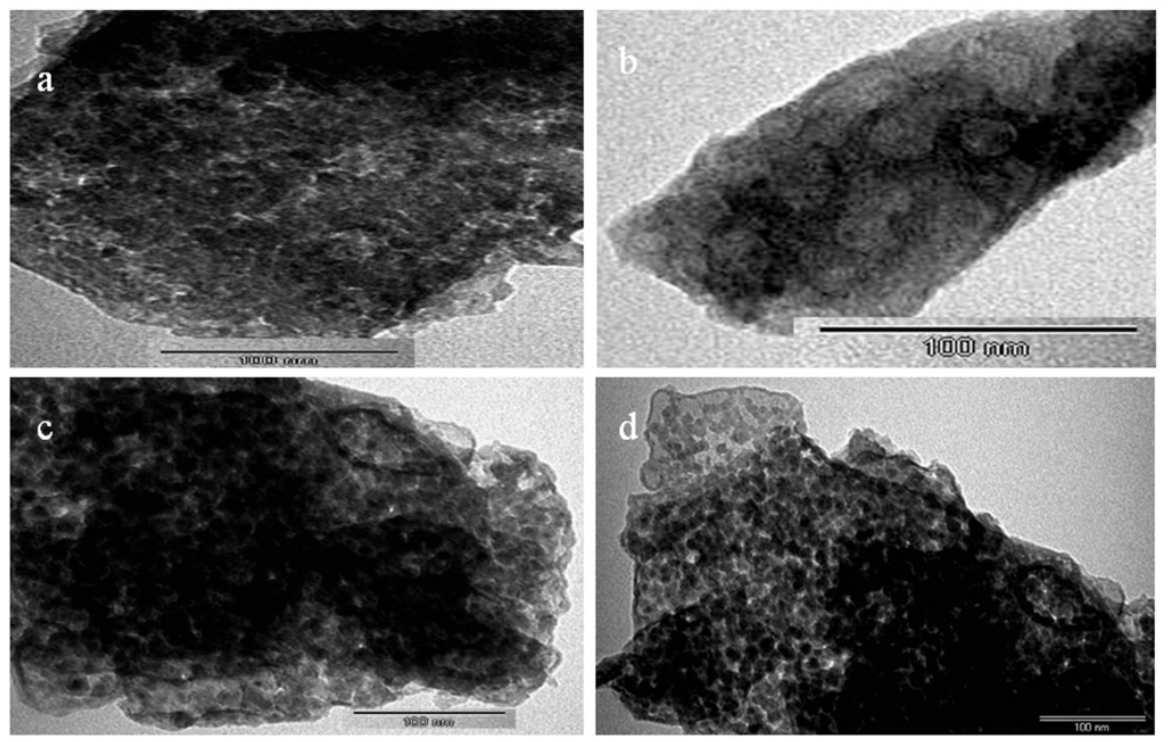

Figure 7. Transmission electron microscopy (TEM) images of $(\mathbf{a}, \mathbf{b})$ nanohybrid NH2 and (c,d) nanohybrid NH3. 


\subsection{Raman Spectroscopy}

Raman spectroscopy is considered a well-known technique for exploring graphitic materials. Figure 8a presented the Raman spectrum of the prepared graphene. It showed the characteristic bands of graphic materials that were known as D and G bands [26]. The first band was at $1362 \mathrm{~cm}^{-1}$ reference to the structural defects and disorder graphitic carbon while, the second band recorded at $1600 \mathrm{~cm}^{-1}$ represented order graphitic carbon by confirming the existence of the hybrid sp ${ }^{2}$ atoms of carbon in graphene layers. By forming the nanohybrids based on the prepared graphene oxide, the main bands of graphene oxide were slightly shifted to lower wavenumbers for the nanohybrids $\mathrm{NH} 1, \mathrm{NH} 2$ and NH3. In case of the nanohybrid NH1, Figure $8 \mathrm{~b}$ showed the main bands at $1331 \mathrm{~cm}^{-1}$ and $1586 \mathrm{~cm}^{-1}$ by considering the presence of graphene sheets in the matrix of the layered structure of NH1. The observed shift for these bands indicates the strong interaction between the sheets of graphene oxide and the nanolayers of the LDH. New bands were observed at $1043 \mathrm{~cm}^{-1}$ and $516 \mathrm{~cm}^{-1}$. The new bands were due to $\mathrm{M}-\mathrm{O}-\mathrm{C}$ and $\mathrm{M}-\mathrm{O}-\mathrm{M}$ ( $\mathrm{M}$ is metal atoms) [27]. It indicated the presence of an interaction between graphene sheets and the layers of LDH. In case of the nanohybrids NH2 and NH3, similar results were observed. The intensity of the $\mathrm{D}$ band was higher for the nanohybrids than that of the pure graphene, which confirms the interaction between graphene sheets with an LDH structure [28].

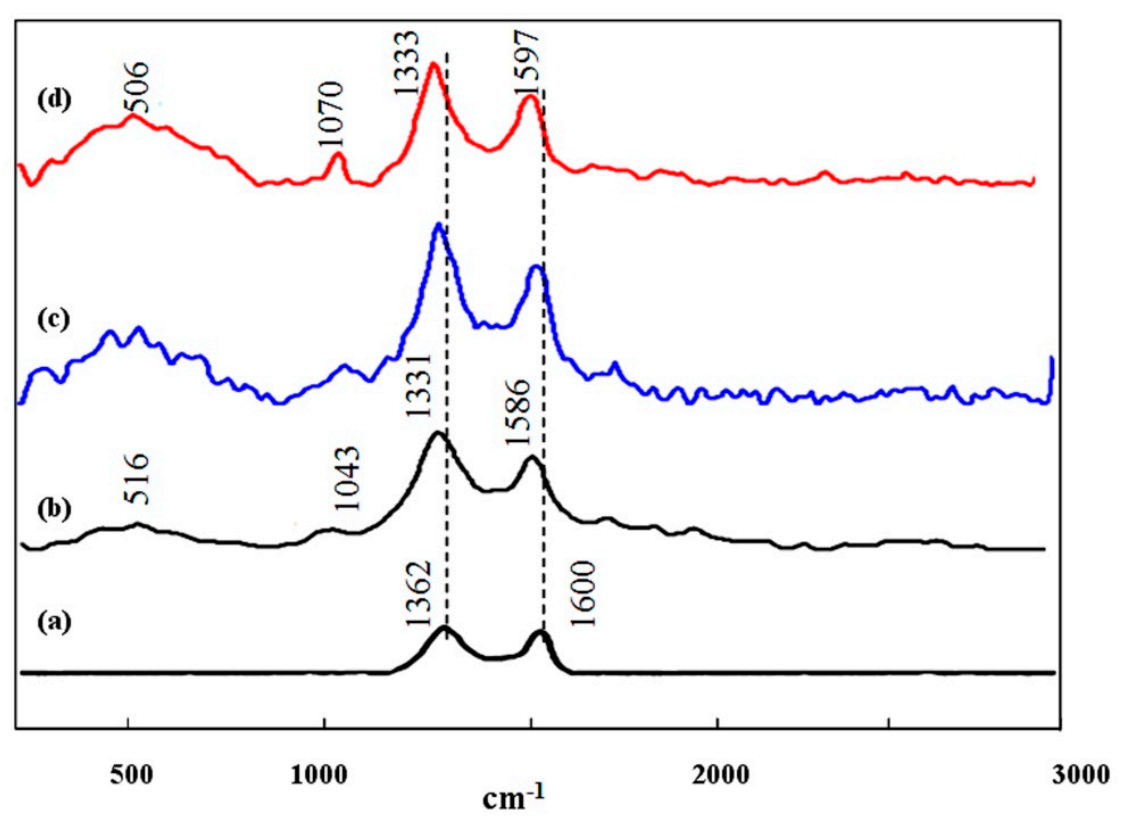

Figure 8. Raman spectra of (a) prepared graphene, (b) nanohybrid NH1, (c) nanohybrid NH2 and (d) nanohybrid NH3.

\subsection{Fourier Transform Infrared Spectroscopy}

The Fourier Transform infrared (FT-IR) spectroscopy was applied to compare between the function groups of the prepared LDH and the nanohybrids. Table 1 summarized the bands of the functions groups of the LDH and the nanohybrids as well as graphene. The main four function groups of LDH were observed as reported in Table 1, which confirms the presence of $\mathrm{OH}$ groups, water molecules and hydrogen bonds alongside with the carbonate anions. Comparing with the structure of LDH, nanohyrids $\mathrm{NH} 1, \mathrm{NH} 2$ and $\mathrm{NH} 3$ contained the same function groups that indicated the combination between LDH with graphene oxide did not change their nanolayered structures in agreement with X-ray diffraction results. Additionally, Table 1 confirmed the oxide form of graphene sheets. The carbonate function group was clearly indicated in the spectrum of graphene oxide. 
Table 1. Infrared spectra results of the prepared materials.

\begin{tabular}{cccccc}
\hline \multirow{2}{*}{ Assignment } & \multicolumn{5}{c}{ Samples (Wavenumbers, $\mathbf{c m}^{-\mathbf{1}}$ ) } \\
\cline { 2 - 6 } & Zn-A1 LDH & NH1 & NH2 & NH3 & Graphene \\
\hline$v_{\mathrm{O}-\mathrm{H}}$ & 3418 & 3407 & 3431 & 3404 & - \\
Absorption bands (C-H) or H-bond & 2988 & 2986 & 3048 & 2915 & 2916 \\
$\delta_{\mathrm{H}_{2} \mathrm{O}}$ & 1649 & 1606 & 1637 & 1637 & 1698 \\
Absorption bands (COO-) & 1429 & 1355 & 1360 & 1434 & 1562 \\
\hline
\end{tabular}

\subsection{Purification of Water}

The concentrations of some selected anions and heavy metals of interest for water quality were analyzed in a fresh sample of tap water from the domestic water network. The results of the analyzed sample were reported in Table 2.

Table 2. Original concentrations of elements of interest for water quality in the analyzed sample.

\begin{tabular}{cccc}
\hline Anions & $\mathbf{m g} / \mathbf{L}$ & Heavy Metal & $\mathbf{~ m g} / \mathbf{L}$ \\
\hline Bromide & 16.2 & Lead & 0.25 \\
Hydrogen phosphate & 0.35 & - & - \\
Fluoride & 0.98 & Cadmium & 0.23 \\
Chloride & 246 & - & - \\
Sulfate & 117 & - & - \\
\hline
\end{tabular}

The five different materials, previously mentioned, were examined for the water purification experiment GO, LDH, NH3, NH2, and NH1(a) with $\mathrm{W} / \mathrm{V}=10 \mathrm{~g} / \mathrm{L}$, while $\mathrm{NH} 1$ (b) and $\mathrm{NH} 1$ (c) were tested with $\mathrm{W} / \mathrm{V}=20 \mathrm{~g} / \mathrm{L}$ and $30 \mathrm{~g} / \mathrm{L}$; respectively. Additionally, five anions were tested in a water sample for the following adsorption experiments: $\mathrm{Br}^{-}, \mathrm{HPO}_{4}{ }^{2-}, \mathrm{F}^{-}, \mathrm{Cl}^{-}$and $\mathrm{SO}_{4}{ }^{2-}$ as well as two heavy metals, $(\mathrm{Cd}$ and $\mathrm{Pb})$. The behavior of these different anions to be adsorbed to the different materials prepared is illustrated in Figure 9. In fact, three different performances were noted. The first behavior was reported for both anions $\mathrm{Br}^{-}$and $\mathrm{HPO}_{4}{ }^{2-}$. The removal efficiency (RE) of $100 \%$ was achieved with all types of nanohybrids $\mathrm{NH} 1, \mathrm{NH} 2$ and $\mathrm{NH} 3$. In contrast, adsorption by the parent structures of $\mathrm{LDH}$ was reported to be approximately $5 \%$ and $70 \%$ to $\mathrm{HPO}_{4}{ }^{2-}$ and $\mathrm{Br}^{-}$; respectively. The second attitude was noticed for both $\mathrm{SO}_{4}{ }^{2-}$ and $\mathrm{Cl}^{-}$ions. Their adsorption was poor $(20 \%-30 \%)$ by the parent structure LDH, but gradually improved relative to increasing the amount of GO in structures prepared as well as increasing the W/V factor. However, the maximum $\mathrm{RE} \%$ for $\mathrm{SO}_{4}{ }^{2-}$ and $\mathrm{Cl}^{-}$ions was calculated as $\sim 80 \%$ for $\mathrm{NH} 1$ (W/V $=30 \mathrm{~g} / \mathrm{L}$ ). The obtained results by the current study showed enlargement in the removal percentage of the mentioned anions in comparison to the results concluded by Hatami et al. [29] who tested the removal of some anions from standard aqueous solution using $\mathrm{Zn}-\mathrm{Al} \mathrm{LDH}$ only. They noted that the removal percentage for both hydrogen phosphate and sulfate from model mixed standards was $80 \%$ and $20 \%$, respectively, whereas all materials studied did not eliminate chloride from the solution. Some other LDHs with different compositions were only tested for chloride removal by Lv et al. [30] from synthetic aqueous medium. The percentage of removal ranged from $21 \%$ up to $64 \%$ according to different hybrids applied. These are still below the results of this study. 


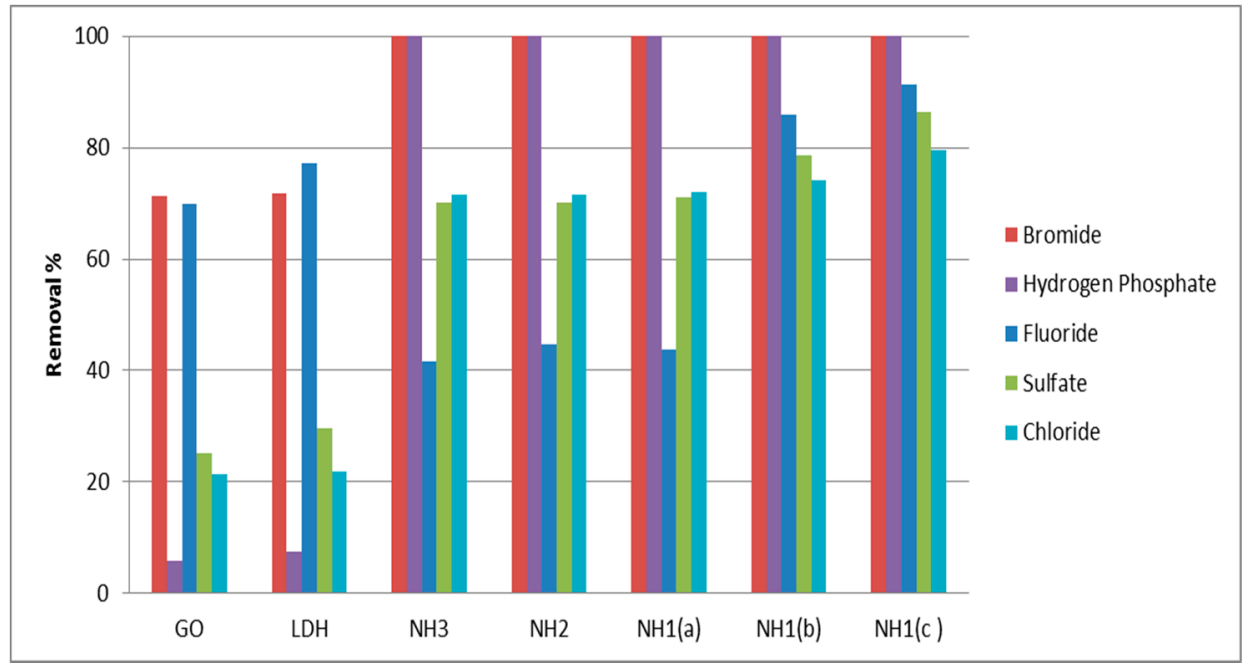

Figure 9. Removal efficiency of selected anions toward the different structures prepared: (a) W/V $=10 \mathrm{~g} / \mathrm{L}$, (b) $\mathrm{W} / \mathrm{V}=20 \mathrm{~g} / \mathrm{L},(\mathbf{c}) \mathrm{W} / \mathrm{V}=30 \mathrm{~g} / \mathrm{L}$.

Lastly, the RE\% for fluoride was 70\% and 78\% for GO and ZnAl-LDH (pristine structures) respectively, while it achieved up to $91 \%$ by the NH1 structure (W/V $=30 \mathrm{~g} / \mathrm{L})$. This result is higher than what was reported by Elhalil et al. [31] who mentioned the RE\% of $75 \%$ for fluoride in real groundwater sample using calcined $\mathrm{Mg} / \mathrm{Al}-\mathrm{LDH}$. Additionally, the contact time required by the current study for removal of the fluoride ion was $5 \mathrm{~h}$ only, whereas Elhalil et al. [31] was $16 \mathrm{~h}$ alongside with $\mathrm{pH}$ adaptation. Another study for removal of the fluoride ion from aqueous solution was carried out by Kameda et al. [32] who applied Mg-Al-LDH. Kameda et al. were able to remove $60 \%$ of fluoride ions prepared in synthetic solution with adjusting parameters such as $\mathrm{pH}$, temperature, etc. However, the results by Zhang et al. [33] indicated that the Li-Al LDHs can be efficiently used to remove fluoride from water with maximum percentage removal (97\%) within $1 \mathrm{~h}$. This satisfactory adsorption equilibrium should be combined with adjusting the adsorption conditions as well as using a pure single standard of the fluoride ion, which is not a normal case in the industrial field.

Hence, one can conclude that occurrence of GO alongside with LDH enhanced the removal efficiency of the tested anions naturally found in tap water. Moreover, it was observed that the modified materials NH1, NH2 and NH3 (same W/V =10 g/L) showed almost the same RE\% for all anions studied. However, the nanohybrid NH1 with $(\mathrm{W} / \mathrm{V}=30 \mathrm{~g} / \mathrm{L})$ is highly recommended for the best anion removal from real water samples.

The removal efficiency of two important heavy metals related to the water quality issue $(\mathrm{Pb} \&$ Cd) was tested by applying all structures prepared as shown in Figure 10. The trend of adsorption of both metals toward all synthesized materials was almost the same except for Zn-Al-LDH. RE\% for $\mathrm{Cd}$ and $\mathrm{Pb}$ ions by the pure graphene structure was $73 \%$ and $65 \%$, while for $\mathrm{Zn}-\mathrm{Al}-\mathrm{LDH}$ was $26.5 \%$ and $77 \%$, respectively. RE\% was improved with all the prepared nanohybrids NH1, NH2 and NH3 in comparison to the pristine structures. Additionally, slightly increasing RE was observed according to the order of NH3, NH2 and NH1. The nanohybrid NH1 with $(\mathrm{W} / \mathrm{V}=30)$ was highly nominated, once more, for the best $\mathrm{Cd}$ and $\mathrm{Pb}$ removal (approximately 90\%) from real water samples among prepared materials. 


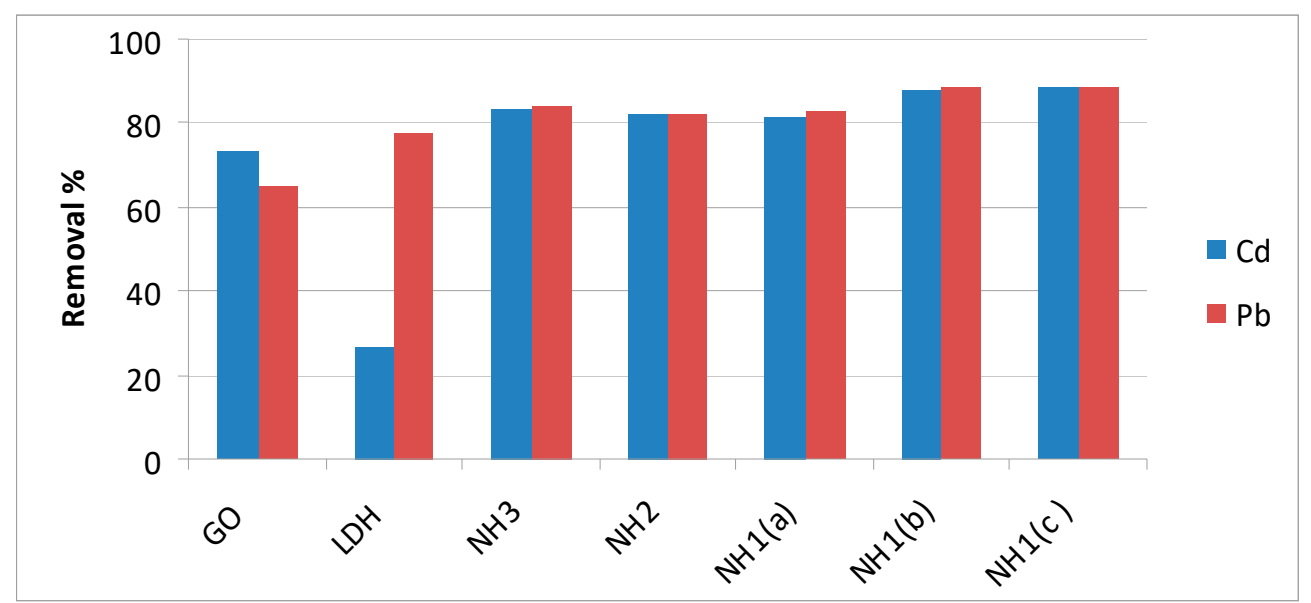

Figure 10. Removal efficiency of selected heavy metals toward the different structures prepared: (a) $\mathrm{W} / \mathrm{V}=10 \mathrm{~g} / \mathrm{L},(\mathbf{b}) \mathrm{W} / \mathrm{V}=20 \mathrm{~g} / \mathrm{L}$, (c) $\mathrm{W} / \mathrm{V}=30 \mathrm{~g} / \mathrm{L}$.

The obtained results are in agreement with both Huang et al. [34] as well as Baruah et al. [35]. Although the current research and these two studies applied GO and LDH by different composition and synthesis methods, the main finding for all, including this work, presented that the removal percentage for $\mathrm{Cd}$ and $\mathrm{Pb}$ ions in aqueous solution ranged from $90 \%$ to $95 \%$. However, it is important to declare that the current work was done on a real fresh water sample without any optimization to experiment conditions. In contrast with using an LDH composite only, the removal percentage for both $\mathrm{Cd}$ and $\mathrm{Pb}$ ions did not exceed 31\% even when experimental conditions ( $\mathrm{pH}, \mathrm{T}$ and contact time) were adapted as reported by Pérez et al. [36]. Hence, one can conclude that occurrence of GO alongside with LDH enhanced the removal efficiency of all tested ions naturally found in tap water.

To sum up, the present effort would be recognized as a pioneer application for removal of both anions and heavy metals naturally found in a tap water sample by the prepared nanohybrids without experimental optimization. These results concluded that the prepared nanohybrids could work as dual function materials for elimination of different anions from the natural water as well as heavy metals at the same time.

\section{Conclusions}

The current study applied the sheets of graphene oxide and the nanolayers of $\mathrm{Zn}-\mathrm{Al} \mathrm{LDHs}$ to produce well-designed nanohybrids to act as dual-effect adsorbents for removing different anions and two heavy metals from natural water. In this trend, these nanohybrids caused complete removal for sulfate and chloride anions. In addition, they removed the majority of fluoride, bromide and phosphate anions from the natural water. At the same time, these nanohybrids showed another positive effect for removal some heavy metals (cadmium and lead). It confirmed that the prepared nanohybrids can be used as dual-function nanohybrid materials for water purification. This dual-effect of the nanohybrids could be explained by creating new porous structures inside the materials prepared.

In order to explain the behavior of the prepared nanohybrids toward removal of anions and heavy metals from natural water, the surface area and the porous structure of the nanohybrids NH1, NH2 and NH3 were studied and compared with the parent materials using Brunauer-Emmett-Teller (BET) [37] and Barrett, Joyner, and Halenda (BJH) [38] methods as illustrated in Table 3. The surface properties and porous structures of the prepared materials were determined by full adsorption-desorption isotherm of nitrogen gas at $77 \mathrm{~K}\left(-196^{\circ} \mathrm{C}\right)$. A Quanta-chrome Nova sorption system was applied to perform these adsorption-desorption processes. Using the adsorption data, average pore radius, pore volume and specific surface area were assessed through the Brunauer-Emmett-Teller equation. According to the Barrett, Joyner, and Halenda method, the pore size distribution and surface areas were determined by analyzing the desorption data. 
Table 3. Surface parameters for the nanohybrids based on $\mathrm{Zn}-\mathrm{Al}$ layered double hydroxides (LDH) and graphene oxide using Brunauer-Emmett-Teller equation [37] and Barrett, Joyner, and Halenda method [38].

\begin{tabular}{cccccc}
\hline Samples & $\begin{array}{c}\text { Graphene Oxide } \\
(\mathbf{W t .} \%)\end{array}$ & $\begin{array}{c}\mathbf{S}_{\text {BET }} \\
\left(\mathbf{m}^{\mathbf{2}} \mathbf{g}\right)\end{array}$ & $\begin{array}{c}\mathbf{S}_{\text {BJH }} \\
\left(\mathbf{m}^{\mathbf{2}} / \mathbf{g}\right)\end{array}$ & $\begin{array}{c}\mathbf{V p}_{\text {BJH }} \\
\left(\mathbf{c m}^{\mathbf{3}} / \mathbf{g}\right)\end{array}$ & $\begin{array}{c}\mathbf{R p}_{\text {BJH }} \\
(\mathbf{n m})\end{array}$ \\
\hline Zn-Al LDH & 0.0 & 5.60 & 3.30 & 0.0120 & 1.80 \\
NH1 & 3.50 & 33.40 & 42.0 & 0.080 & 3.50 \\
NH2 & 2.30 & 61.50 & 75.30 & 0.130 & 3.20 \\
NH3 & 1.30 & 60.30 & 57.0 & 0.290 & 3.50 \\
\hline
\end{tabular}

$\mathrm{Rp}_{\mathrm{BJH}}, \mathrm{Vp}_{\mathrm{BJH}}$ and $\mathrm{S}_{\mathrm{BJH}}$, pore radius, total pore volume and specific surface area calculated by the BJH method, respectively; $\mathrm{S}_{\mathrm{BET}}$, specific surface area calculated by the BET method.

The prepared nanohybrids represented high efficiency for removing five anions and two heavy metals even though the sizes of these species are different. This behavior was due to the sharp increasing of the surface area of the nanohybrids in comparison to pure LDH. The surface area of the pure LDH was $5.60 \mathrm{~m}^{2} / \mathrm{g}$ as reported in Table 3. By combining LDH with $3.5 \%$ of graphene oxide, the surface area of the nanohybrid NH1 increased to be $33.4 \mathrm{~m}^{2} / \mathrm{g}$. In the same trend, the surface area of both NH2 and NH3 became $61.50 \mathrm{~m}^{2} / \mathrm{g}$ and $60.3 \mathrm{~m}^{2} / \mathrm{g}$, respectively. It means that the high efficiency of the nano hybrids can be due to the growth of the surface area. The porous structures of the nanohybrids were better than that of LDH because of new pores with a bigger size being created. The data in Table 3 indicated that the total pore volume of the LDH increased from $0.0120 \mathrm{~cm}^{3} / \mathrm{g}$ to the range of $0.08-0.290 \mathrm{~cm}^{3} / \mathrm{g}$ after combinating with graphene oxide. These pores were more suitable for trapping the different kinds of anions and heavy metals at the same time. These porous structures of the nanohybrids could be obtained by the nanolayers of LDH interacting with the nanosheets of graphene oxide, which act as a substrate for building the nanohybrids. According to our results, we conclude that the advantage of the dual-effect property of these nanohybrids enhanced the removal process of the different kinds of anions and the heavy metals from water in one stage only. It is likely the first time effective materials for eliminating of mono-valent, di-valent, and tri-valent anions were prepared alongside heavy metals in one step.

Supplementary Materials: The following are available online at http://www.mdpi.com/1996-1944/13/11/2524/s1.

Author Contributions: Conceptualization, O.S. and S.M.A.; Methodology, O.S.; Software, M.F.E.; Validation, O.S., S.M.A. and M.F.E.; Formal analysis, M.A.-A.; Investigation, S.M.A.; Resources, W.I.M.E.-A.; Data curation, O.S. and W.I.M.E.-A.; Writing — original draft preparation, O.S. and S.M.A.; Writing-review and editing, O.S. and M.F.A.; Visualization, M.F.A.; Supervision, O.S.; Project administration, S.M.A.; Funding acquisition, S.M.A. All authors have read and agreed to the published version of the manuscript.

Funding: This research was funded by the Deanship of Scientific Research, Imam Abdulrahman Bin Faisal University (IAU), Saudi Arabia, grant number 2017-045-IRMC and The APC was funded by 2017-045-IRMC.

Acknowledgments: The authors acknowledge the financial support from the Deanship of Scientific Research (DSR), Imam Abdulrahman Bin Faisal University (IAU), Saudi Arabia (Grant Application No. 2017-045-IRMC). Special appreciations are extended to King Faisal University for the facilities and the technical support. Deep thanks for Khalid Batoo from King Abdullah Institute for Nanotechnology (KAIN), King Saud University (KSU), Abdulaziz Abdulrahman Alsaadi from King Fahd University of Petroleum and Minerals (KFUPM), and Abdulhakeem Kh. Aldosary, Imam Abdulrahman Bin Faisal University (IAU), Saudi Arabia for their technical assistance.

Conflicts of Interest: The authors declare no conflict of interest.

\section{References}

1. World Health Organization (WHO). Guidelines for drinking-water quality. In Chemical Fact Sheet; World Health Organization: Geneva, Switzerland, 2004; pp. 296-459.

2. Strobl, R.O.; Robillard, P.D. Network design for water quality monitoring of surface freshwaters: A review. J. Environ. Manag. 2008, 87, 639-648. [CrossRef] [PubMed]

3. Järup, L. Hazards of heavy metal contamination. Br. Med. Bull. 2003, 68, 167-182. [CrossRef] [PubMed] 
4. Kawarada, K.; Haneishi, K.; Iida, T. Pore structure and performance for drinking water treatment of activated carbon prepared from sugi thinning from water source forest in Tokyo. Wood Ind. 2005, 60, 398-401.

5. Wei, Y.C.; Yang, Z.S.; Alsaedi, A.H.; Wang, X. Understanding the adsorption mechanism of Ni(II) on graphene oxides by batch experiments and density functional theory studies. Sci. China Chem. 2016, 59, 412-419.

6. Soyluoglu, M.; Ersan, M.S.; Ateia, M.; Karanfil, T. Removal of bromide from natural waters: Bromide-selective vs. conventional ion exchange resins. Chemosphere 2020, in press. [CrossRef]

7. Vikrant, K.; Kim, K.H.; Ok, Y.S.; Tsang, D.C.W.; Tsange, Y.F.; Giria, B.S.; Singha, R.S. Engineered/designer biochar for the removal of phosphate in water and wastewater. Sci. Total Environ. 2018, 616-617, 1242-1260. [CrossRef]

8. Ashane, W.; Fernando, M.; Ilankoon, I.M.S.K.; Syed, T.H.; Yellishettyb, M. Challenges and opportunities in the removal of sulphate ions in contaminated mine water: A review. Miner. Eng. 2018, 117, 74-90.

9. Angst, U.; Elsener, B. Mechanism of electrochemical chloride removal. Corros. Sci. 2007, 49, 4504-4522.

10. Costantino, U.; Nocchetti, M.; Sisani, M.; Vivani, R. Recent progress in the synthesis and application of organically modified hydrotalcites. Z. Kristallogr. 2009, 224, 273-281. [CrossRef]

11. Parida, K.M.; Dash, S.K. Adsorption of $\mathrm{Cu}^{2+}$ on spherical Fe-MCM-41 and its application for oxidation of adamantane. J. Hazard. Mater. 2010, 179, 642-649. [CrossRef]

12. Jing, Y.; Zhou, Z.; Cabreraa, C.R.; Chen, Z. Graphene, inorganic graphene analogs and their composites for lithium ion batteries. J. Mater. Chem. A 2014, 2, 12104-12122. [CrossRef]

13. Zhao, M.Q.; Zhang, Q.; Huang, J.Q.; Wei, F. Hierarchical Nanocomposites Derived from Nanocarbons and Layered Double Hydroxides-Properties, Synthesis, and Applications. Adv. Funct. Mater. 2012, 22, 675-694. [CrossRef]

14. Goh, K.H.; Lim, T.T.; Dong, Z.L. Removal of arsenate from aqueous solution by nanocrystalline $\mathrm{Mg} / \mathrm{Al}$ layered double hydroxide: Sorption characteristics, prospects, and challenges. Water Sci. Technol. 2010, 61, 1411-1417. [CrossRef] [PubMed]

15. Li, M.; Zhu, J.E.; Zhang, L.; Chen, X.; Zhang, H.; Zhang, F.; Xu, S.; Evans, D.G. Facile synthesis of NiAl-layered double hydroxide/graphene hybrid with enhanced electrochemical properties for detection of dopamine. Nanoscale 2011, 3, 4240-4246. [CrossRef] [PubMed]

16. Wang, X.; Zhang, L. Green and facile production of high-quality graphene from graphite by the combination of hydroxyl radical and electrical exfoliation. RSC Adv. 2018, 8, 40621-40631. [CrossRef]

17. Gonazlez, M.A.; Pavlovic, I.; Rojas-Delgado, R.; Barriga, C. Removal of $\mathrm{Cu}^{2+}, \mathrm{Pb}^{2+}$ and $\mathrm{Cd}^{2+}$ by layered double hydroxide-humate hybrid. Sorbate and sorbent comparative studies. Chem. Eng. J. 2014, 254, 605-611. [CrossRef]

18. Yuan, X.; Wang, Y.; Wang, J.; Zhou, C.; Tang, Q.; Rao, X. Calcined graphene/MgAl-layered double hydroxides for enhanced Cr (VI) removal. Chem. Eng. J. 2013, 221, 204-213. [CrossRef]

19. Zhao, X.; Cao, J.; Zhao, J.; Hu, G.; Dang, Z.A. hybrid Mg-Al layered double hydroxide/graphene nanostructure obtained via hydrothermal synthesis. Chem. Phys. Lett. 2014, 605-606, 77-80. [CrossRef]

20. Qiu, T.; Yang, J.; Bai, X.; Wang, Y. The preparation of synthetic graphite materials with hierarchical pores from lignite by one-step impregnation and their characterization as dye absorbents. RSC Adv. 2019, 9, 12737-12746. [CrossRef]

21. Saber, O.; Aljaafari, A.; Alomair, H.A.; Alshoaibi, A. Novel Strategy for Producing Nanoplatelets to be Used as Building Blocks for Shaping Nanofibers through Layered Double Hydroxides and Poly Vinyl Alcohol. Chem. Sel. 2019, 4, 4293-4300. [CrossRef]

22. Saber, O.; Aljaafari, A.; Alshoaibi, A.; Al-Yaari, M.; Osama, M. A Novel Route for Controlling and Improving the Texture of Porous Structures Through Dual Growth of Alumina Nanoparticles and Carbon Nanotubes Using Explosion Process of Solid Fuel. J. Mater. Res. Technol. 2020, 9, 67-75. [CrossRef]

23. Wu, F.; Liang, J.; Peng, Z.; Liu, B. deposition and characterization of Zn-Al layered double hydroxides (LDHs) films on magnesium alloy. Appl. Surf. Sci. 2014, 313, 834-840. [CrossRef]

24. Shamsayai, M.; Yamini, Y.; Asiabi, H. Fabrication of zwitterionic histidine/layered double hydroxide hybrid nanosheets for highly e_cient and fast removal of anionic dyes. J. Colloid Interface Sci. 2018, 529, 255-264. [CrossRef] [PubMed]

25. Zeng, F.L.; Yuan, X.L.; Zou, W.J.; Huang, X.J.; Mo, S.S.; Yuan, D.S. Synthesis of highly graphitic mesoporous carbon using Ni-Fe double-layered hydroxide as both template and catalyst precursor. Carbon 2013, 28, 563-564. [CrossRef] 
26. Atchudana, R.; Edison, T.N.J.I.; Perumal, S.; Shanmugam, M.; Lee, Y.R. Direct solvothermal synthesis of zinc oxide nanoparticle decorated graphene oxide nanocomposite for efficient photodegradation of azo-dyes. J. Photochem. Photobiol. A Chem. 2017, 337, 100-111. [CrossRef]

27. Li, X.; Zhang, Y.; Xing, W.; Li, L.; Xue, Q.; Yan, Z. Sandwich-like graphene/polypyrrole/layered double hydroxide nanowires for high-performance supercapacitors. J. Power Sources 2016, 331, 67-75. [CrossRef]

28. Khobragade, P.S.; Hansora, D.P.; Jitendra, N.; Njuguna, J.; Mishra, S. Preparation and analysis of multi-layered hybrid nanostructures. Appl. Clay Sci. 2016, 132-133, 668-674. [CrossRef]

29. Hatami, H.; Fotovat, A.; Halajnia, A. Comparison of adsorption and desorption of phosphate on synthesized Zn-Al LDH by two methods in a simulated soil solution. Appl. Clay Sci. 2018, 152, 333-341. [CrossRef]

30. Lv, L.; Sun, P.; Gu, Z.; Du, H.; Pang, X.; Tao, X.; Xu, R.; Xu, L. Removal of chloride ion from aqueous solution by $\mathrm{ZnAl}-\mathrm{NO}_{3}$ layered double hydroxides as anion-exchanger. J. Hazard. Mater. 2009, 161, 1444-1449. [CrossRef]

31. Elhalil, A.; Qourzal, S.; Mahjoubi, F.Z.; Elmoubarki, R.; Farnane, M.; Tounsadi, H.; Sadiq, M.; Abdennouri, M.; Barka, N. Defluoridation of groundwater by calcined $\mathrm{Mg} / \mathrm{Al}$ layered double hydroxide. Emerg. Contam. 2016, 2, 42-48. [CrossRef]

32. Kameda, T.; Oba, J.; Yoshioka, T. Recyclable Mg-Al layered double hydroxides for fluoride removal: Kinetic and equilibrium studies. J. Hazard. Mater. 2015, 300, 475-482. [CrossRef] [PubMed]

33. Zhang, T.; Li, Q.; Xiao, H.; Lu, H.; Zhou, Y. Synthesis of Li-Al Layered Double Hydroxides (LDHs) for Efficient Fluoride Removal. Ind. Eng. Chem. Res. 2012, 51, 11490-11498. [CrossRef]

34. Huang, Q.; Chen, Y.; Yu, H.; Yan, L.; Zhang, J.; Wang, B.; Du, B.; Xing, L. Magnetic graphene oxide/MgAllayered double hydroxide nanocomposite: One-pot solvothermal synthesis, adsorption performance and mechanisms for $\mathrm{Pb}^{2+}, \mathrm{Cd}^{2+}$, and $\mathrm{Cu}^{2+}$. Chem. Eng. J. 2018, 341, 1-9. [CrossRef]

35. Baruah, A.; Mondal, S.; Sahoo, L.; Gautam, U.K. Ni-Fe-layered double hydroxide/N-doped graphene oxide nanocomposite for the highly efficient removal of $\mathrm{Pb}(\mathrm{II})$ and $\mathrm{Cd}(\mathrm{II})$ ions from water. J. Solid State Chem. 2019, 280, 120963. [CrossRef]

36. Pérez, M.R.; Pavlovic, I.; Barriga, C.; Cornejo, J.; Hermosín, M.C.; Ulibarri, M.A. Uptake of $\mathrm{Cu}^{2+}, \mathrm{Cd}^{2+}$ and $\mathrm{Pb}^{2+}$ on $\mathrm{Zn}-\mathrm{Al}$ layered double hydroxide intercalated with EDTA. Appl. Clay Sci. 2006, 32, 245-251. [CrossRef]

37. Brunauer, S.; Emmett, P.H.; Teller, E. Adsorption of gases in multimolecular layers. J. Am. Chem. Soc. 1938, 60, 309-319. [CrossRef]

38. Barrett, E.P.; Joyner, L.G.; Halenda, P.H. The determination of pore volume and area distributions in porous substances. I. Computations from nitrogen isotherms. J. Am. Chem. Soc. 1951, 73, 373-380. [CrossRef] 